\title{
Influence of growth kinetics on graphene domains shape under atmospheric pressure chemical vapor deposition
}

\author{
Mopeli Samuel Fabiane ${ }^{1,2}$ (D) $\cdot$ Moshawe Jack Madito ${ }^{3} \cdot$ Ncholu Manyala $^{1}$
}

Received: 23 May 2020 / Revised: 30 September 2020 / Accepted: 5 October 2020 / Published online: 23 October 2020

(c) The Author(s) 2020

\begin{abstract}
In this work, the role of gas kinetics in the growth of lobed graphene domains by atmospheric pressure chemical vapor deposition (AP-CVD) is elucidated by sandwiching $\mathrm{Cu}$ foil between $\mathrm{Si} / \mathrm{SiO}_{2}$ wafers. Two different growths were carried out: (1) $\mathrm{A} \mathrm{Cu}$ foil was placed at the center of a quartz tube in AP-CVD for graphene growth and (2) another $\mathrm{Cu}$ foil was sandwiched between $\mathrm{Si} / \mathrm{SiO}_{2}$ wafers to alter the nucleation growth kinetics of graphene domains to mimic those in low-pressure chemical vapor deposition (LP-CVD). From the scanning electron microscopy (SEM) images, the graphene domains of the sandwiched $\mathrm{Cu}$ foil displayed mostly four-lobed, parallel-sided domains which are usually obtained under LP-CVD as compared to $\mathrm{Cu}$ foil without sandwiching which showed typical hexagonal graphene domains of AP-CVD. The Raman spectroscopy confirmed that the domains are single-layer graphene. An electron backscatter diffraction (EBSD) showed that the $\mathrm{Cu}$ foil is predominantly (001). The results of this study agree with the theoretical predictions of growth kinetics in graphene synthesis by CVD and showed that it is possible to obtain single-layer graphene domains which are usually obtained under LP-CVD by restricting the gas flux through the boundary layer.
\end{abstract}

\section{Graphic abstract}

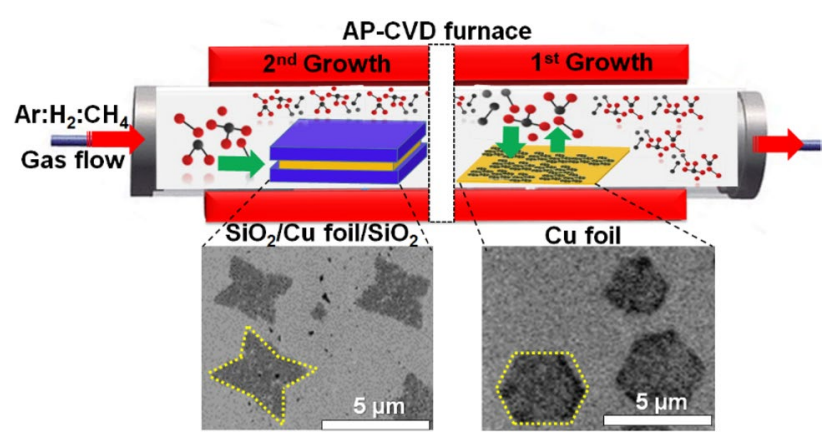

Keywords Graphene $\cdot$ AP-CVD $\cdot \mathrm{Cu}$ foil $\cdot$ Graphene domains $\cdot$ Gas kinetics

Mopeli Samuel Fabiane

ms.fabiane@nul.1s

1 Department of Physics, Institute of Applied Materials, SARChI Chair in Carbon Technology and Materials, University of Pretoria, Pretoria 0028, South Africa

2 Department of Physics and Electronics, National University of Lesotho, P.O. 180, Roma, Lesotho

3 iThemba LABS, National Research Foundation, P.O. Box 722, Somerset West, Cape Town 7129, South Africa

\section{Introduction}

Graphene, a monolayer of carbon atoms in a two-dimensional (2D) honeycomb lattice, has several unique properties that make it an ideal material for research as well as potential applications [1, 2]. Since the discovery of the first isolated graphene prepared by mechanical exfoliation of graphite [3], several chemical approaches for growing large-area graphene have been developed. Chemical vapor deposition (CVD) is an appealing approach to the production of 
graphene because of its capability for producing large-area, high-quality graphene samples. A spurt of interest in CVD growth of graphene was triggered by the seminal work published by Ruoff's group using low-pressure chemical vapor deposition (LP-CVD) [4].

However, the CVD growth of graphene has revealed multiple challenges due to the need to explore enormous experimental parameter space due to the multiple components involved [5]. A vast majority of published results in this area have relied on the low-pressure CVD recipe for graphene growth. Indeed, low-pressure CVD approach has been shown to be scalable for large graphene film synthesis $[6,7]$; however, it has challenges such as feeding the catalyst foil into a low-pressure reactor, severe evaporation of copper catalyst and requirement of a vacuum system compatible with flammable precursor gases [5]. The last two aspects do not constitute major problems for a research-oriented laboratory, but they do translate into substantial obstacles for industrial-scale graphene production and would contribute to increased production costs [5].

Although CVD graphene growth on $\mathrm{Cu}$ surface has a simplistic view, the growth mechanism or kinetics is complex and depends on growth background pressure. Bhaviripudi et al. [8] proposed a model for CVD graphene growth on low carbon solid solubility catalyst (Fig. 1) in which the carbon species first (1) diffuse through the boundary layer onto $\mathrm{Cu}$ surface (i.e., a low carbon solid solubility catalyst), (2) get adsorbed on the catalyst surface, and (3) decompose to form active carbon species which (4) diffuse on the surface of the catalyst to form nucleation sites and (5) attachment of active $\mathrm{C}$ species to nucleation sites to materialize graphene ( $\mathrm{C}=\mathrm{C}$ bonds formation), and (6) inactive species (such as hydrogen) get desorbed from the surface, form molecular hydrogen, and diffuse away from the surface through the boundary layer and are eventually swept away by the bulk gas flow. In this model, there are two fluxes of the active species that coexist: (1) flux of active species through the boundary layer and (2) the rate at which the active species are consumed at the surface of the catalyst to form the graphene lattice/domains (see Eqs. 1 and 2) below [8]:
$J_{\mathrm{mt}}=h_{\mathrm{g}}\left(C_{\mathrm{g}}-C_{\mathrm{s}}\right)$

$J_{\mathrm{sr}}=K_{\mathrm{s}} C_{\mathrm{s}}$

where the $J_{\mathrm{mt}}$ is the flux of active species through the boundary layer $(\delta), J_{\mathrm{sr}}$ is the flux of consumed active species at the surface, $h_{\mathrm{g}}$ is the mass transport coefficient, $K_{\mathrm{s}}$ is the surface reaction constant, $C_{\mathrm{g}}$ is the concentration of the gas in the bulk and $C_{\mathrm{s}}$ is the concentration of the active species at the catalyst surface. The slower of the two processes is the rate-limiting step during graphene growth. At steady state, three regimes result in which (1) $h_{\mathrm{g}} \gg K_{\mathrm{s}}$ (surface reaction-controlled regime), (2) $h_{\mathrm{g}} \sim K_{\mathrm{s}}$ (mixed regime) and $h_{\mathrm{g}} \ll K_{\mathrm{s}}$ (mass transport-limited regime) [8]. According to Ref.[8], under atmospheric pressure CVD (AP-CVD) at high growth temperatures $\left(\sim 1000{ }^{\circ} \mathrm{C}\right)$ the gas diffusion through the boundary layer is slower than the surface reactions $\left(K_{\mathrm{s}}>>h_{\mathrm{g}}\right)$ and this is the rate-limiting step. However, as the pressure is lowered, the boundary layer also increases, but the increase in gas diffusion through the layer is significantly higher compared to an increase in the thickness of the boundary layer [8]. Therefore, the overall effect is that the mass transport coefficient, $h_{\mathrm{g}}$, increases as a result of lowering the total pressure and the diffusion through the boundary layer is enhanced and no longer the rate-limiting step under normal growth conditions $\left(h_{\mathrm{g}} \gg K_{\mathrm{s}}\right)$. Under these conditions (i.e., LP-CVD), the surface reaction regime is rate limiting, and as long as the temperature is maintained uniform across the length of the wafer, the thickness of the graphene is uniform [8]. Therefore, the influence of the $\mathrm{Cu}$ surface and orientations are more noticeable in the early stage of graphene growth. Murdock et al. have demonstrated that under LP-CVD the growth of graphene domains is dictated by $\mathrm{Cu}$ crystallographic orientations [9].

In this study, we show that restricting the gas supply to the $\mathrm{Cu}$ foil by placing it between $\mathrm{Si} / \mathrm{SiO}_{2}$ wafers under AP-CVD graphene growth alters the nucleation growth kinetics of graphene domains to mimic those in LP-CVD.
Fig. 1 a Processes involved during graphene synthesis using low carbon solid solubility catalysts $(\mathrm{Cu})$ in a CVD process. b Mass transport and surface reaction fluxes under steadystate conditions. Reprinted with permission from Ref. [8]. Copyright (2010) American Chemical Society (a)

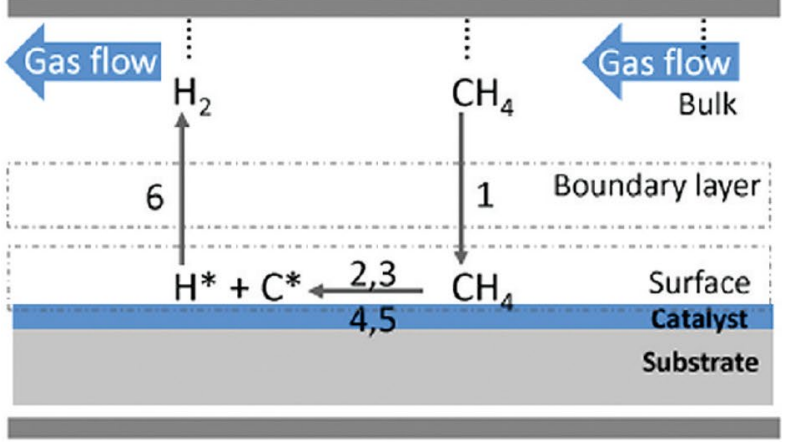

(b)

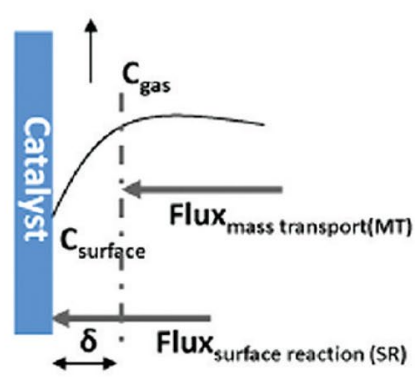




\section{Experimental}

$\mathrm{Cu}$ foil samples $\left(\sim 40 \times 40 \mathrm{~mm}^{2}\right)$ were obtained from a high-purity (99.8\%) 25- $\mu \mathrm{m}$-thick annealed $\mathrm{Cu}$ foil for graphene growth from Alfa Aesar. Samples were annealed under $\mathrm{Ar}(300 \mathrm{sccm})$ and $\mathrm{H}_{2}(9 \mathrm{sccm})$ flow for $30 \mathrm{~min}$ at $1000{ }^{\circ} \mathrm{C}$ before the growth of graphene. Two different growths were carried out, as illustrated in Scheme 1. In the first growth process, $\mathrm{Cu}$ foil was placed at the center of a quartz tube in AP-CVD for graphene growth at $1000{ }^{\circ} \mathrm{C}$ from a mixture of gases, $\mathrm{Ar}(300 \mathrm{sccm}): \mathrm{H}_{2}(9 \mathrm{sccm}): \mathrm{CH}_{4}$ $(10 \mathrm{sccm})$ for $10 \mathrm{~s}$. Immediately after growth, the $\mathrm{CH}_{4}$ flow was stopped and samples were rapidly cooled down by pushing the quartz tube to the cooler region of the furnace and at less than $80{ }^{\circ} \mathrm{C}$ the samples were off-loaded from the tube. In the second growth process, a $\mathrm{Cu}$ foil was sandwiched between $\mathrm{Si} / \mathrm{SiO}_{2}$ wafers and placed at the center of a quartz tube in AP-CVD for graphene growth at $1000{ }^{\circ} \mathrm{C}$ from a mixture of gases, $\mathrm{Ar}(300 \mathrm{sccm}): \mathrm{H}_{2}(9 \mathrm{sccm})$ : $\mathrm{CH}_{4}(15 \mathrm{sccm})$ for $60 \mathrm{~s}$. After growth, some of the samples were transferred from $\mathrm{Cu}$ foil to $\mathrm{SiO}_{2} / \mathrm{Si}$ substrates using bubbling method $[10,11]$ for further characterization. A WITec alpha 300RAS + confocal Raman system (WITec $\mathrm{GmbH}$ ) was used for both imaging and spectroscopy with the laser power set below $2 \mathrm{~mW}$ to minimize heating effects. The excitation wavelength used was set to $532 \mathrm{~nm}(2.33 \mathrm{eV})$ through a numerical aperture of 0.9 and $100 \times$ magnifications, which allows an image spatial resolution of about $360 \mathrm{~nm}$. A high-resolution scanning electron microscope (SEM) Zeiss Ultra Plus 55 FE-SEM operated at $1.0 \mathrm{kV}$ was used to investigate the surface morphology of the graphene samples. The topographical images were obtained using a Dimension Icon atomic force microscope (AFM) by Bruker AXS with NanoScope
Analysis software in ScanAsyst mode. Electron backscatter diffraction (EBSD) analysis of a $\mathrm{Cu}$ foil was performed in a LEO 1525 field emission gun scanning electron microscope at an acceleration voltage of $25 \mathrm{kV}$ using the Oxford INCA crystal software.

\section{Results and discussion}

In our experimental setup, the $\mathrm{SiO}_{2} / \mathrm{Si}$ slabs act as a barrier that eliminates the boundary layer and hence the rate-limiting reaction is the surface reaction $\left(K_{\mathrm{s}}\right)$ as in the LP-CVD. Therefore, the gas molecules diffuse through the limited space in the interface between the $\mathrm{Si}$ slabs and $\mathrm{Cu}$ surface with a low partial pressure compared to gas on the $\mathrm{Cu}$ foil without slabs, and thereafter, hydrocarbon decomposes on the $\mathrm{Cu}$ surface to supply carbon for graphene growth. As a result, the graphene domains on $\mathrm{Cu}$ foil between the slabs have a decreased growth rate and improved crystal quality. This hypothesis is further confirmed by the following experimental findings.

Figure 2 presents the SEM images of the graphene domains obtained from the two growth processes which display hexagonal graphene islands for the $\mathrm{Cu}$ foil without slabs (first growth) and lobed graphene domains (mostly four-lobed, parallel-sided domains) for sandwiched $\mathrm{Cu}$ foil (second growth) similar to those obtained under LPCVD $[9,12,13]$. As discussed in Fig. 1, graphene growth mechanisms and results from LP-CVD and AP-CVD differ. Graphene growth on $\mathrm{Cu}$ in the LP-CVD method is a surfacelimited diffusion process of carbon species [14]. Graphene domains, in this case, may show symmetric patterns as sixlobed snowflake-like structures [14-16] and four-lobed starlike structures $[12,14]$. On the other hand, growth in the AP-CVD is not self-limiting and is likely to be a surface
Scheme 1. An illustration of two different graphene growths carried out on $\mathrm{Cu}$ foil and $\mathrm{Cu}$ foil sandwiched between $\mathrm{Si} /$ $\mathrm{SiO}_{2}$ wafers in AP-CVD

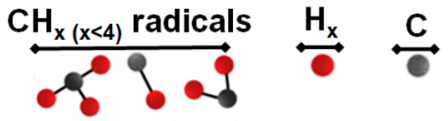

AP-CVD furnace

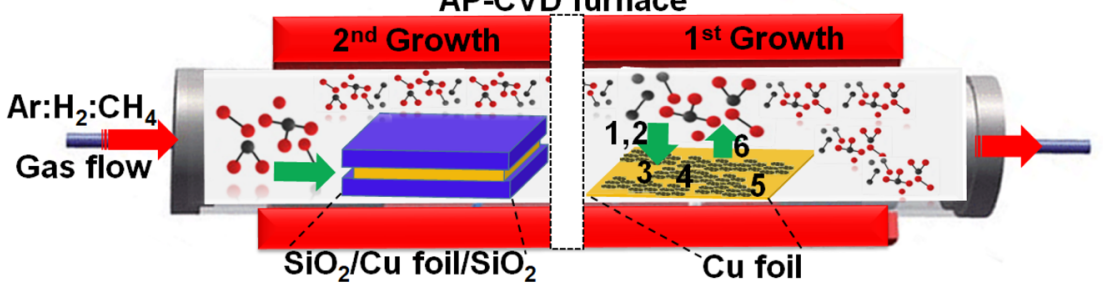

1. Diffusion of $\mathrm{CH}_{4}$ through the boundary layer onto $\mathrm{Cu}$ surface

2. Adsorption (and desorption) of $\mathrm{CH}_{4}$ on the catalyst surface

3. Decomposition of $\mathrm{CH}_{4}$ into active $\mathrm{C}$ species $\left(\mathrm{CH}_{3}, \mathrm{CH}_{2}, \mathrm{CH}\right.$ and $\left.\mathrm{C}\right)$ and $\mathrm{H}_{2}$

4. Aggregation of active $\mathrm{C}$ species and formation of nucleation sites

5. Attachment of active $\mathrm{C}$ species to nucleation sites to form graphene (domains)

6. Desorption of inactive species from the catalyst surface 

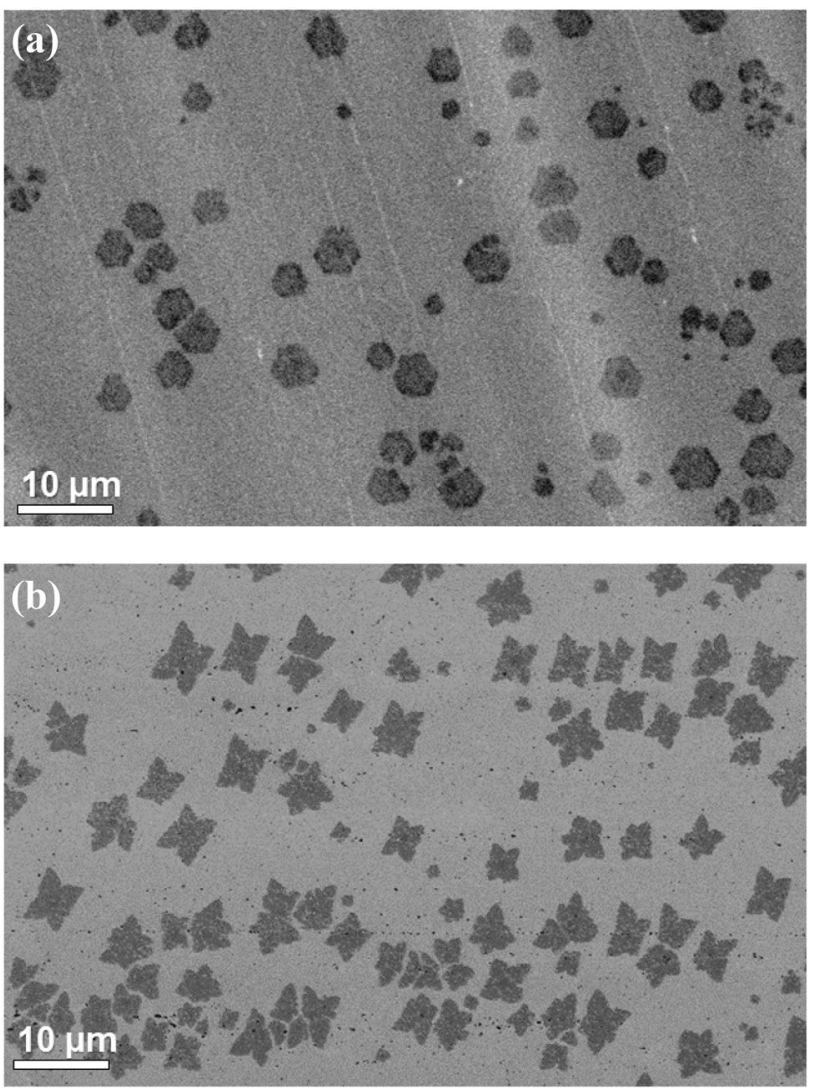

Fig. 2 SEM images of graphene domains grown on a $\mathrm{Cu}$ foil without $\mathrm{SiO}_{2} / \mathrm{Si}$ slabs and $\mathbf{b} \mathrm{Cu}$ foil sandwiched between $\mathrm{Si} / \mathrm{SiO}_{2}$ slabs

adsorption process in which extended growth time increases the number of graphene layers [8], and the graphene islands exhibit a hexagonal shape, suggesting a growth mechanism that is determined by the graphene structure rather than the underlying copper substrates [14, 17, 18].

Figure 3a shows an AFM image of one of the lobed graphene domains transferred onto $\mathrm{SiO}_{2} / \mathrm{Si}$ substrate. From AFM image, the height of the domain is $\sim 1 \mathrm{~nm}$ which could be attributed to a single-layer graphene domain. The typical graphene wrinkles are also visible on the domain, and the white spots are residues from the transfer process. Moreover, Raman spectroscopy, a well-established tool to probe, among others, the number of graphene layers, and the interlayer interactions and stacking order in graphene samples, was used to characterize the graphene domains. Typically, the main Raman characteristic features of highquality graphene are the G-band mode $\left(\sim 1590 \mathrm{~cm}^{-1}\right)$ and the 2D-band mode $\left(\sim 2680 \mathrm{~cm}^{-1}\right)$ which originate from the normal first-order Raman scattering process (the inplane bond stretching displacements of $s p^{2}$ carbon atoms, i.e., $E_{2 \mathrm{~g}}$ symmetry) and the second-order double resonance Raman process that involves two in-plane transverse optical mode (iTO) phonons near the $K$-point, respectively
[19]. However, in the defective graphene, these Raman features include the disorder-induced mode (D-band at $\sim 1350 \mathrm{~cm}^{-1}$ ) which originates from a double resonance Raman process involving inter-valley scattering of iTO phonon and defect near the $K$-point [19]. Figure $3 b$ displays the Raman G-peak intensity mapping of the lobed graphene domain, and the corresponding average spectra are shown in Fig. 3(c). It can be seen from the G-peak intensity mapping that the $G$ peaks intensities scale range at the center of the domain is twice that of the overall domain which suggests that the domain is monolayer graphene with bilayer graphene starting to grow from the initial nucleation center. In graphene, the G-band intensity shows behavior that follows a linear trend as the number of layers increases from mono- to multilayer graphene [19]. Furthermore, the representative average Raman spectra of the domain (Fig. 3c) display a typical Raman spectrum of monolayer graphene and bilayer graphene (i.e., domain center). Figure 3d, e show Raman 2D peaks full width at half maximum (FWHM) mapping and the corresponding $2 \mathrm{D}$-to-G peaks intensities ratio $\left(I_{2 \mathrm{D}} / I_{\mathrm{G}}\right)$ mapping of graphene domain, respectively. The FWHMs and $I_{2 \mathrm{D}} / I_{\mathrm{G}}$ ratios are around $30 \mathrm{~cm}^{-1}$ and $\sim 3-4$, and these indicate that the domain is monolayer graphene with a bilayer center $(2 \mathrm{D}$ $\mathrm{FWHM} \approx 50 \mathrm{~cm}^{-1}$ and $\left.I_{2 \mathrm{D}} / I_{\mathrm{G}} \approx 1\right)$. Fig. $3 \mathrm{f}$ displays the D-to-G peaks intensities ratio $\left(I_{\mathrm{D}} / I_{\mathrm{G}}\right)$ mapping with an average value in the range of $\sim 0.1-0.2$. This low $I_{\mathrm{D}} / I_{\mathrm{G}}$ ratio indicates that the graphene domain is of high quality, as would be expected under LP-CVD conditions due to a high vacuum. Nevertheless, at higher growth temperatures $\left(\sim 1000{ }^{\circ} \mathrm{C}\right), \mathrm{AP}-\mathrm{CVD}$ grows high-quality graphene.

For a microstructural analysis of the annealed $\mathrm{Cu}$ foil, an SEM $10.0 \mathrm{kV}$ primary electron beam was scanned across the foil surface to obtain its microstructural image, as shown in Fig. 4a, which displays the average grain size of $\sim 30 \mu \mathrm{m}$. The surface normal projected inverse pole figure EBSD map of Alfa Aesar Cu foil (with color key inset) is presented in Fig. 4b. This figure reveals that the annealed $\mathrm{Cu}$ foil used in this study is predominantly (001). Previously published reports have shown that an annealed Alfa Aesar $\mathrm{Cu}$ foil for graphene growth is mainly $(001)[9,20]$. Moreover, Murdock et al. demonstrated the influence of crystallographic orientations of polycrystalline $\mathrm{Cu}$ substrates on the formation of CVD graphene domains and identified four predominant cases under LP-CVD [9]:

(i) Four-lobed, parallel-sided domains on $\mathrm{Cu}(101)$, orientated in one direction [ -101$]$.

(ii) Four-lobed, parallel-sided domains on $\mathrm{Cu}(001)$, orientated in two $\sim 90^{\circ}$ rotated directions with equal probability.

(iii) Six-lobed, star-shaped domains on tilted and highindex $\mathrm{Cu}$ grains, e.g., $\mathrm{Cu}(103)$. 
Fig. 3 a An AFM image of graphene domain grown on $\mathrm{Cu}$ foil sandwiched between $\mathrm{SiO}_{2} / \mathrm{Si}$ slabs and transferred onto $\mathrm{SiO}_{2} /$ Si substrate. b Raman G-peak intensity mapping of the graphene domain transferred onto $\mathrm{SiO}_{2} / \mathrm{Si}$ substrate. $\mathrm{c}$ The average Raman spectra of the G-peak intensity mapping in (a) (green (top) spectrum corresponds to monolayer graphene and red (bottom) spectrum to bilayer graphene). d Raman 2D-peak FWHM mapping. e $I_{2 \mathrm{D}} / I_{\mathrm{G}}$ mapping and $\mathbf{f} I_{\mathrm{D}} / I_{\mathrm{G}}$ mapping of the graphene domain in (b) (a)

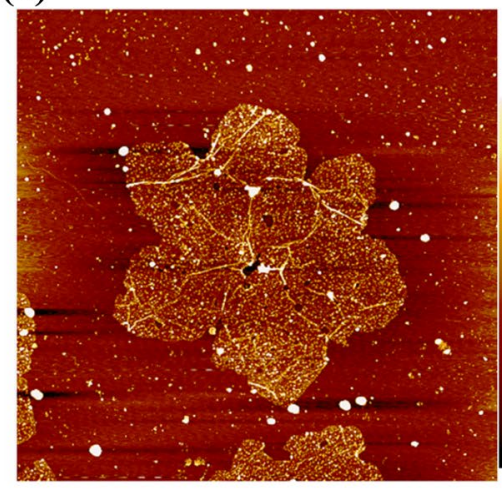

(b)
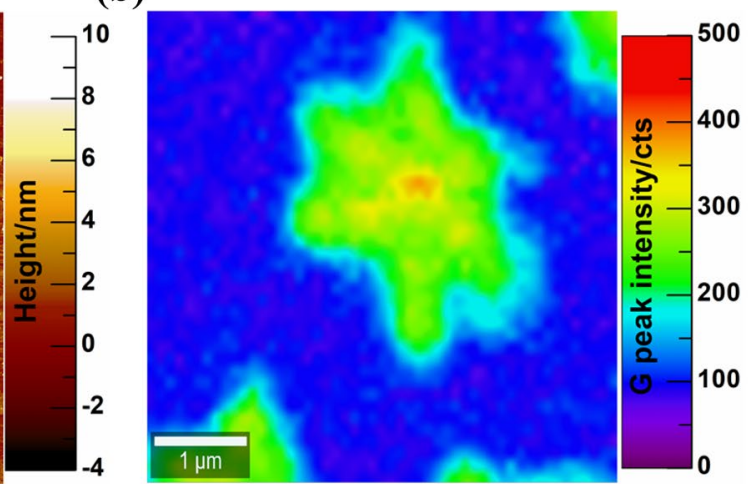

(c)

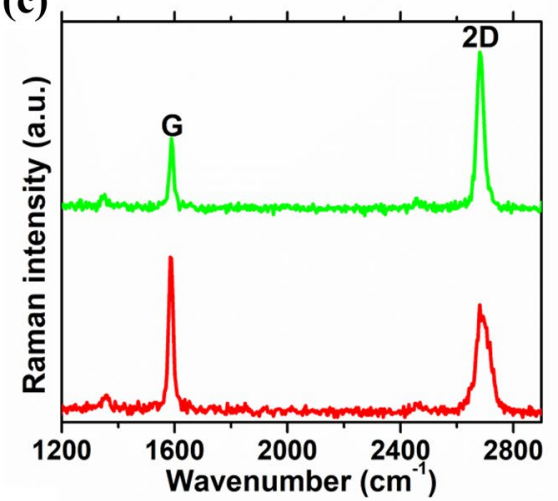

(e)

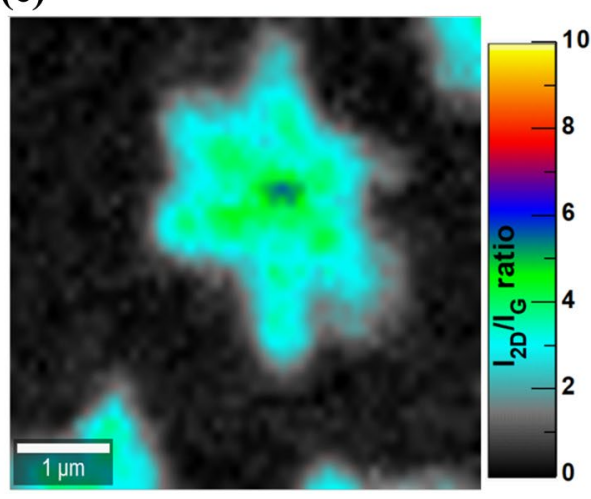

(d)

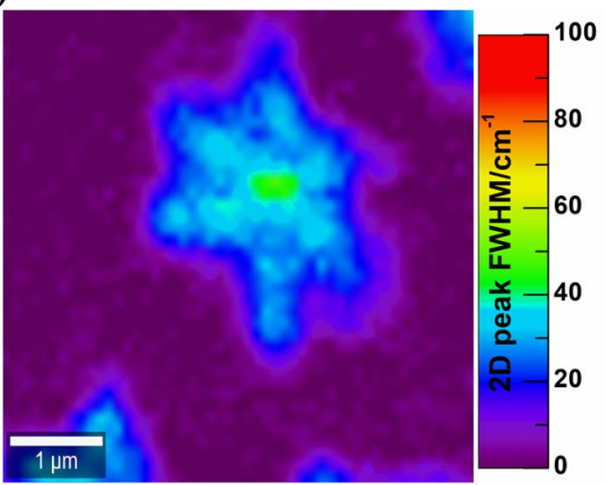

(f)

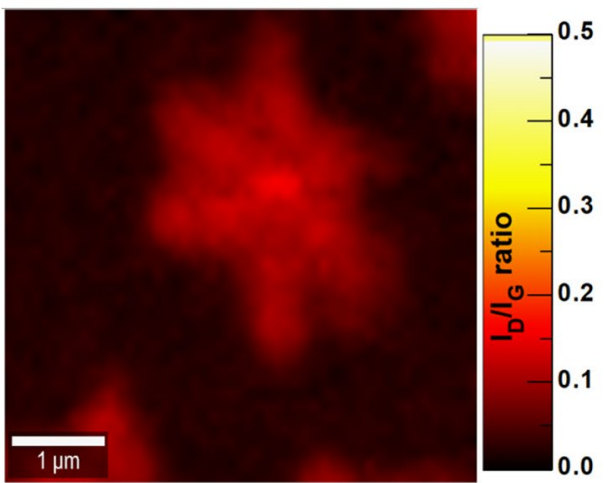

(iv) Hexagonal-edged elongated domains on orientations close to $\mathrm{Cu}(111)$ and $\mathrm{Cu}(535)$, orientated in one direction.

Therefore, in our study, an observed lobed graphene domain on Alfa Aesar $\mathrm{Cu}(001)$ foil which is usually observed under LP-CVD confirms that the growth kinetics of graphene domains of a sandwiched $\mathrm{Cu}$ foil mimic those in LP-CVD.

\section{Conclusion}

In conclusion, we have demonstrated a simple reproducible method to alter the nucleation growth kinetics of graphene domains to mimic those in LP-CVD by restricting the gas supply to the $\mathrm{Cu}$ foil by placing it between $\mathrm{Si} / \mathrm{SiO}_{2}$ wafers under AP-CVD graphene growth. Two different AP-CVD 
(a)

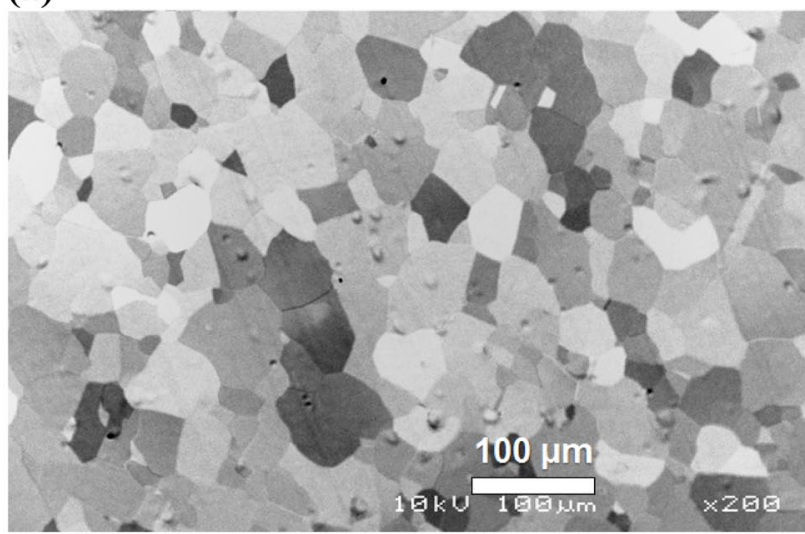

(b)

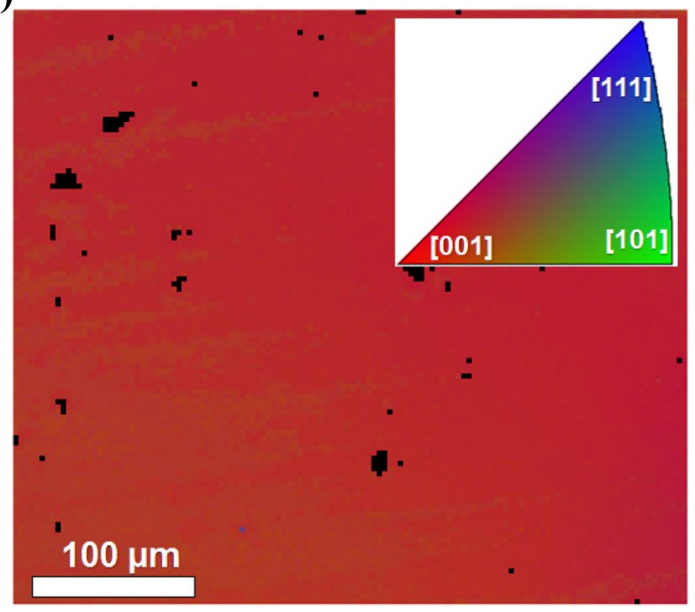

Fig. 4 a SEM microstructure image of the annealed $\mathrm{Cu}$ foil surface. b Surface normal projected inverse pole figure EBSD map of Alfa Aesar $\mathrm{Cu}$ foil (with color key inset)

graphene growths were carried out on a $\mathrm{Cu}$ foil, i.e., on a $\mathrm{Cu}$ foil without sandwiching and on $\mathrm{Cu}$ foil sandwiched between $\mathrm{Si} / \mathrm{SiO}_{2}$ wafers to alter the nucleation growth kinetics of graphene domains to mimic those in LP-CVD. The results of the graphene domains of the sandwiched $\mathrm{Cu}$ foil displayed lobed graphene domains which are usually obtained under LP-CVD as compared to $\mathrm{Cu}$ foil without sandwiching which showed typical hexagonal graphene domains of AP-CVD. Care was taken to have a $\mathrm{Cu}$ foil as flat as possible between the flat $\mathrm{Si}$ wafers, and the space between the $\mathrm{Cu}$ foil and the $\mathrm{SiO}_{2} / \mathrm{Si}$ slab was estimated to be approximately $50 \mu \mathrm{m}$. The size $\left(\sim 40 \times 40 \mathrm{~mm}^{2}\right)$ of the samples, i.e., $\mathrm{Cu}$ foil sandwiched between $\mathrm{Si} / \mathrm{SiO}_{2}$ wafers, was limited by the inner diameter of the quartz tube; however, the sample size can be upscaled. Our findings are essential for the production of uniform high-quality, largearea graphene under AP-CVD conditions mimicking LPCVD conditions.
Acknowledgements This study is based on research supported by the South African Research Chairs Initiative of the Department of Science and Technology (SARChI-DST) and the National Research Foundation (NRF) (Grant No. 97994). M.F thanks the University of Pretoria and the NRF for financial support during his PhD studies. M.F acknowledges support from the LRSM, through the US National Science Foundation MRSEC, Grant No. DMR-1120901.

Open Access This article is licensed under a Creative Commons Attribution 4.0 International License, which permits use, sharing, adaptation, distribution and reproduction in any medium or format, as long as you give appropriate credit to the original author(s) and the source, provide a link to the Creative Commons licence, and indicate if changes were made. The images or other third party material in this article are included in the article's Creative Commons licence, unless indicated otherwise in a credit line to the material. If material is not included in the article's Creative Commons licence and your intended use is not permitted by statutory regulation or exceeds the permitted use, you will need to obtain permission directly from the copyright holder. To view a copy of this licence, visit http://creativecommons.org/licenses/by/4.0/.

\section{References}

1. Geim AK, Novoselov KS (2007) The rise of graphene. Nat Mater 6:183-191

2. Xia F, Mueller T, Lin Y-M, Valdes-Garcia A, Avouris P (2009) Ultrafast graphene photodetector. Nat Nanotechnol 4:839-843. https://doi.org/10.1038/nnano.2009.292

3. Novoselov KS, Geim AK, Morozov SV, Jiang D, Zhang Y, Dubonos SV, Grigorieva IV, Firsov AA (2004) Electric field effect in atomically thin carbon films. Science 306:666-669. https://doi. org/10.1126/science.1102896

4. Li X, Cai W, An J, Kim S, Nah J, Yang D, Piner R, Velamakanni A, Jung I, Tutuc E, Banerjee SK, Colombo L, Ruoff RS (2009) Large-area synthesis of high-quality and uniform graphene films on copper foils. Science 324:1312-1314. https://doi.org/10.1126/ science. 1171245

5. Vlassiouk I, Fulvio P, Meyer H, Lavrik N, Dai S, Datskos P, Smirnov S (2012) Large scale atmospheric pressure chemical vapor deposition of graphene. Carbon N Y 54:58-67. https://doi. org/10.1016/j.carbon.2012.11.003

6. Bae S, Kim H, Lee Y, Xu X, Park J-S, Zheng Y, Balakrishnan J, Lei T, Ri Kim H, Il Song Y, Kim Y-J, Kim KS, Özyilmaz B, Ahn J-H, Hong BH, Iijima S (2010) Roll-to-roll production of 30 -inch graphene films for transparent electrodes. Nat Nanotechnol 5:574-578

7. Han GHEE (2011) Poly(ethylene co-vinyl acetate)-assisted onestep transfer of ultra-large graphene. NANO 6:59-65. https://doi. org/10.1142/S1793292011002342

8. Bhaviripudi S, Jia X, Dresselhaus MS, Kong J (2010) Role of kinetic factors in chemical vapor deposition synthesis of uniform large area graphene using copper catalyst. Nano Lett 10:4128-4133

9. Murdock AT, Koos A, Ben Britton T, Houben L, Batten T, Zhang T, Wilkinson AJ, Dunin-Borkowski RE, Lekka CE, Grobert N (2013) Controlling the orientation, edge geometry, and thickness of chemical vapor deposition graphene. ACS Nano 7:1351-1359. https://doi.org/10.1021/nn3049297

10. Dodoo-arhin D, Fabiane M, Bello A, Manyala N (2013) Graphene: synthesis, transfer, and characterization for dye-sensitized solar cells applications. Ind Eng Chem Res 52:14160-14168. https:// doi.org/10.1021/ie4017489 
11. Fabiane M, Khamlich S, Bello A, Dangbegnon J, Momodu D, Charlie AT, Fabiane M, Khamlich S, Bello A (2013) Growth of graphene underlayers by chemical vapor deposition Growth of graphene underlayers by chemical vapor deposition. AIP Adv. https://doi.org/10.1063/1.4834975

12. Li X, Magnuson CW, Venugopal A, An J, Suk JW, Han B, Borysiak M, Cai W, Velamakanni A, Zhu Y, Fu L, Vogel EM, Voelkl E, Colombo L, Ruoff RS (2010) Graphene films with large domain size by a two-step chemical vapor deposition process. Nano Lett 10:4328-4334. https://doi.org/10.1021/nl101629g

13. Hwang C, Yoo K, Kim SJ, Seo EK, Yu H, Bir LP (2011) Initial stage of graphene growth on a $\mathrm{Cu}$ substrate. J Phys Chem $\mathrm{C}$ 115:22369-22374

14. Zhao P, Kumamoto A, Kim S, Chen X, Hou B, Chiashi S, Einarsson E, Ikuhara Y, Maruyama S (2013) Self-limiting chemical vapor deposition growth of monolayer graphene from ethanol. J Phys Chem C 117:10755-10763

15. Li X, Magnuson CW, Venugopal A, Tromp RM, Hannon JB, Vogel EM, Colombo L, Ruo RS (2011) Large-area graphene single crystals grown by low-pressure. J Am Chem Soc 133:2816-2819

16. Zhang Y, Zhang L, Kim P, Ge M, Li Z, Zhou C (2012) Vapor trapping growth of single-crystalline graphene flowers: synthesis, morphology, and electronic properties. Nano Lett 12:2810-2816
17. Graphene S, Foils C, Yan Z, Lin J, Peng Z, Sun Z, Zhu Y, Li L, Xiang C, Lo1 E, Kittrell C, Tour JM (2012) Toward the Synthesis of Wafer-Scale. ACS Nano 23:9110-9117

18. Robertson AW, Warner JH (2011) Hexagonal single crystal domains of few-layer graphene on copper foils. Nano Lett 11:1182-1189. https://doi.org/10.1021/nl104142k

19. Ferrari AC, Meyer JC, Scardaci V, Casiraghi C, Lazzeri M, Mauri F, Piscanec S, Jiang D, Novoselov KS, Roth S, Geim AK (2006) Raman spectrum of graphene and graphene layers. Phys Rev Lett 97:187401

20. Madito MJ, Bello A, Dangbegnon JK, Oliphant CJ, Jordaan WA, Momodu DY, Masikhwa TM, Barzegar F, Fabiane M, Manyala N (2016) A dilute $\mathrm{Cu}$ ( Ni ) alloy for synthesis of large-area Bernal stacked bilayer graphene using atmospheric pressure chemical vapour deposition. J Appl Phys. https://doi.org/10.1063/1.49396 48

Publisher's Note Springer Nature remains neutral with regard to jurisdictional claims in published maps and institutional affiliations. 